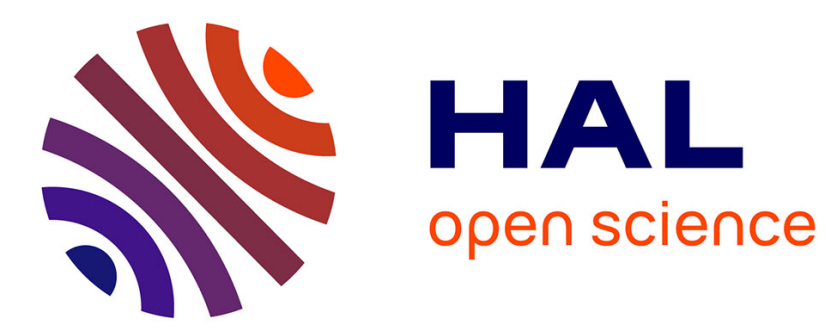

\title{
d Surface states in transition metals
}

\author{
M.C. Desjonquères, F. Cyrot-Lackmann
}

\section{To cite this version:}

M.C. Desjonquères, F. Cyrot-Lackmann. d Surface states in transition metals. Journal de Physique Lettres, 1975, 36 (2), pp.45-47. 10.1051/jphyslet:0197500360204500 . jpa-00231150

\section{HAL Id: jpa-00231150 https://hal.science/jpa-00231150}

Submitted on 1 Jan 1975

HAL is a multi-disciplinary open access archive for the deposit and dissemination of scientific research documents, whether they are published or not. The documents may come from teaching and research institutions in France or abroad, or from public or private research centers.
L'archive ouverte pluridisciplinaire HAL, est destinée au dépôt et à la diffusion de documents scientifiques de niveau recherche, publiés ou non, émanant des établissements d'enseignement et de recherche français ou étrangers, des laboratoires publics ou privés. 


\title{
d SURFACE STATES IN TRANSITION METALS
}

\author{
M. C. DESJONQUÈRES
}

\author{
Laboratoire de Microscopie Ionique, Faculté des Sciences de Rouen, 76130 Mont-Saint-Aignan, France \\ and
}

\section{F. CYROT-LACKMANN}

Institut Laue-Langevin, BP 156 Centre de Tri, 38042 Grenoble Cedex, France

and

\author{
CNRS, Groupe des Transitions de Phases, BP 166, 38042 Grenoble Cedex, France
}

(Reçu le 27 septembre 1974, accepté le 19 décembre 1974)

\begin{abstract}
Résumé. - On calcule les densités d'états locales sur les surfaces de bas indice du nickel et du fer cubique centré dans l'approximation des liaisons fortes en tenant compte de la dégénérescence de la bande $d$ et du transfert de charge. Les résultats montrent l'existence de pics d'états de surface dans la bande sur les surfaces non denses et un élargissement de la bande lorsque le potentiel de surface est suffisamment grand. Ils sont compatibles avec les données expérimentales.
\end{abstract}

\begin{abstract}
The tight-binding model, including $d$ band degeneracy, is used to calculate the local densities of states on low index surfaces of fcc Ni and bcc Fe. Charge transfer effects are investigated. The results show the existence of peaks of surface states inside the band on non dense planes of cleavage and a broadening of the band when the surface perturbing potential is strong enough. They are consistent with experimental data.
\end{abstract}

Surface studies still represent a challenging problem in spite of the recent advances in spectroscopic techniques. These techniques give some partial information about surface densities of states on some cleaved transition metals, such as $\mathrm{Ni}[1], \mathrm{W}[2,3]$ or Mo [4]. But a systematic theoretical study has not yet been made. The density of states is expected to depend on two main factors : the $\mathrm{d}$ band degeneracy and the charge rearrangement near the surface. So far all attempts at treating these effects together have failed : calculations were made either for a narrow $s$ band [5-8] or degeneracy was included but charge transfer effects neglected $[9,10]$.

We present here the first complete set of precise local densities of states (LDS) on low index face s of fcc and boc transitions metals (namely $\mathrm{Ni}$ and $\mathrm{Fe}$ ) taking fully into account $d$ band degeneracy and charge transfer effects. The LDS are obtained within the tight-binding approximation using the moment method and the continued fraction analysis described elsewhere $[8,11]$. We used 22 to 26 moments in order to obtain precise details in the LDS. We found peaks of surface states inside the band on non-dense planes of cleavage for both crystalline structures. In addition surface states can also occur outside the bulk band when the surface perturbing potential is strong enough as will be the case for $\mathrm{Ni}$.
The cleavage of the crystal brings about a change in the electronic distribution near the surface and therefore modifies the potential experienced by electrons. We assume that the perturbation potential is well localized near the surface and we retain only its intraatomic matrix elements between the same atomic orbitals centred on surface atoms. These five matrix elements are supposed to be equal, which is reasonable and thus we have only one tight-binding parameter $\left(U_{0}\right)$ more than in the bulk case. The condition of charge conservation, following from Friedel's sum rule, gives a mean of determining $U_{0}$ self-consistently. It is expressed by the equation :

$$
\Delta N\left(E_{\mathrm{F}}, U_{0}\right)=0
$$

where $\Delta N$ is the variation of the integrated total density of states when cleaving the crystal and $E_{\mathrm{F}}$ is the Fermi level.

Eq. (1) has been used to study the variation of $U_{0}$ with $E_{\mathrm{F}}$ for fcc and boc crystals, neglecting the variation of the LDS sufficiently far from the surface. Figure $1 a$ gives the results obtained for a fec crystal in the dense (111) and non dense (100) planes of cleavage and figure $1 b$ for a boc crystal in the dense (110) and non dense (100) planes of cleavage. As expected, the general behaviour of the perturbing potential is similar for both crystalline structures, 

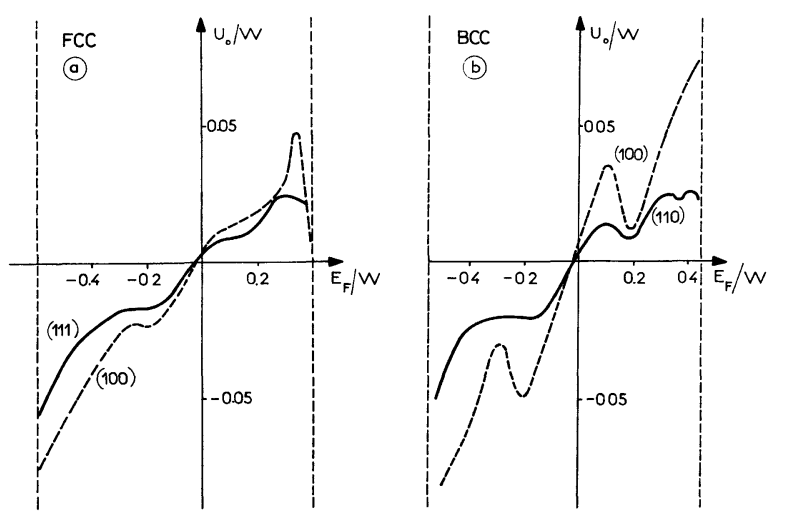

FIG. 1. - Variation of $U_{0} / W$ in terms of $E_{\mathrm{F}} / W\left(U_{0}:\right.$ surface perturbation potential, $E_{\mathrm{F}}:$ Fermi level, $W$ bulk band width). The energy zero is the atomic level. a) fcc crystal : (111) plane (full line) and (100) plane (broken line). b) boc crystal : (110) plane (full line) and (100) plane (broken line).

which means that it is quite insensitive to the details of the bulk density of states. But its absolute value depends on the roughness of the surface and increases with the number of dangling bonds. It vanishes when the Fermi level is slightly below the atomic level i.e. for a nearly half-filled band. Its variation is not monotonic : $U_{0}$ decreases when the Fermi level is located in a peak of the bulk density of states. This is particularly clear for the (100) semi-infinite bcc crystal.

We have then calculated the LDS on clean surfaces of various metals. A systematic study for fcc $\mathrm{Ni}$, hcp Co and bcc Fe will be published elsewhere with more details [12]. Here we will only present the more striking results.

$\mathrm{FCC} . \mathrm{Ni}$

(111)

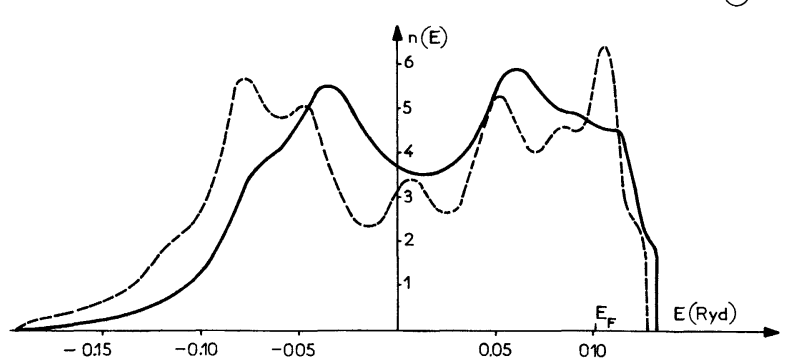

FCC. $\mathrm{Ni}$

(100)

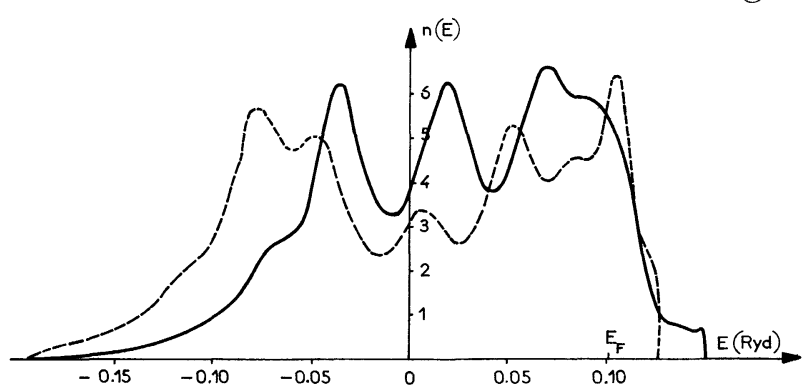

FIG. 2. - The local density of states on the surface of cleaved fcc $\mathrm{Ni}$ compared with the bulk density of states (broken curve). The energy zero is the atomic level. a) (111) plane; b) (100) plane.
Figure $2 a, 2 b$, shows the LDS on the (111) and (100) surfaces of a foc Ni crystal and figure $3 a, 3 b$ the LDS on the (110) and (100) surfaces of a bcc Fe crystal compared with the corresponding bulk density of states (broken curve), when crystal field integrals are neglected.

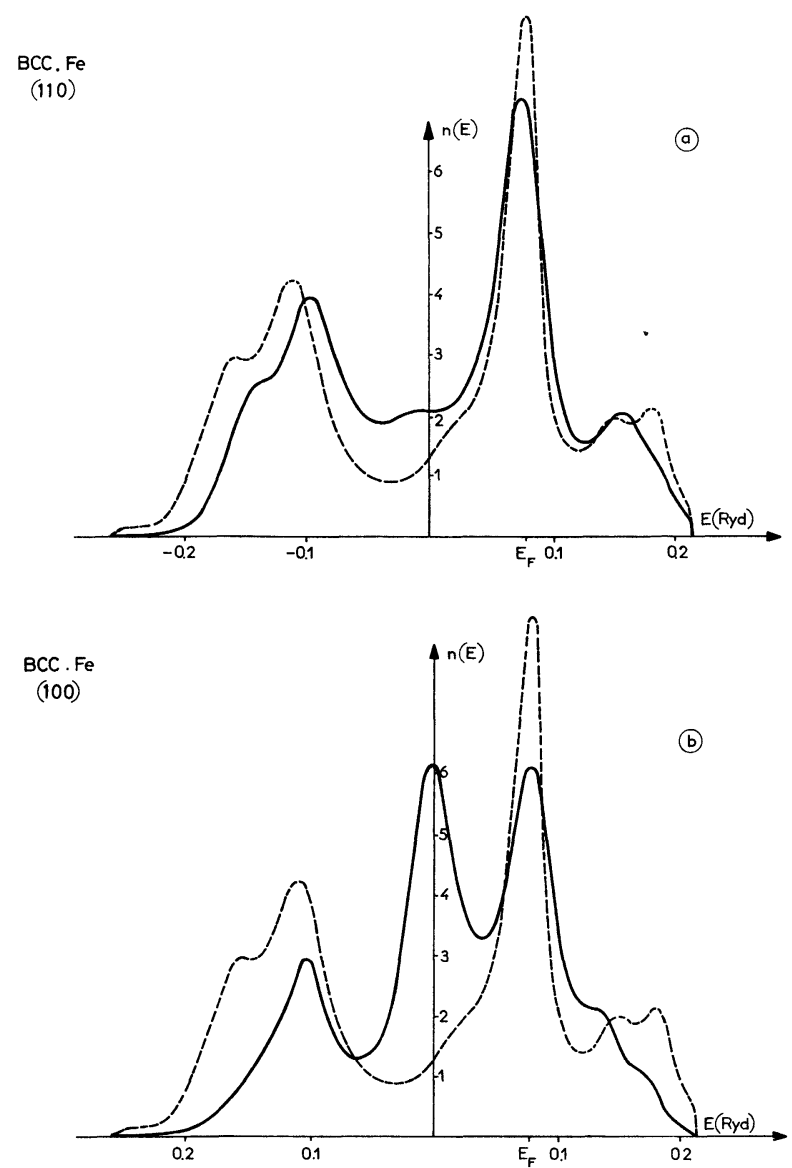

FIG. 3. - The local density of states on the surface of cleaved bcc Fe compared with the bulk density of states (broken curve). The energy zero is the atomic level. a) (110) plane; b) (100) plane.

Some important conclusions can be drawn. Whereas the LDS on dense planes of cleavage resembles the bulk density of states, the LDS on non dense planes of cleavage exhibits a sharp peak near the middle of the band. This peak is absent from the bulk density of states and it disappears as soon as one proceeds into the crystal, as can be seen by computing the LDS on subsurface layers [12]. It is therefore assigned to states localized near the surface. Let us note that these surface states are composed of the five orbitals in almost equal proportions.

The charge transfer at the surface has two main effects. First the states are pushed towards the top of the band i.e. the peaks of the surface states are shifted by approximately $U_{0}$. Second, when $U_{0}$ is strong enough there is a possible broadening of the band, owing to surface states. This happens for semi infinite fcc Ni crystal but not for bcc Fe. The band width increase is small for the (111) Ni plane but for the (100) Ni plane it is not at all negligible being about 
$7.5 \%$. Contrary to the case of surface states inside the band, the surface states here are almost exclusively composed of only one orbital, lying in the surface, $x y$ for $(100) \mathrm{Ni}$ for instance.

To compare with experimental results, it would also be very interesting to know if states with no momentum parallel to the surface give the predominant contribution to the peak of the surface states which appears for non dense planes of cleavage, as was recently obtained theoretically by Sturm and Feder [13] for a (100) cleaved W crystal. We have performed such a calculation for the (100) plane of bcc $\mathrm{Fe}$ and our results are quite different as can be seen in figure 4. There is no peak near $E=0$ and the only peak, at $E=0.081 \mathrm{Ryd}$, corresponds to bulk states. This shows that the peak of surface states is not mainly composed of states with $\mathbf{k}_{\|}=0$.

It would be very interesting to have detailed experimental data to compare with our results. Unfortunately these data are still scarce and their interpretation somewhat uncertain owing to their varying degree of surface sensitivity. However, the observed decrease in the mean width of the $\mathrm{d}$ band on cleaved

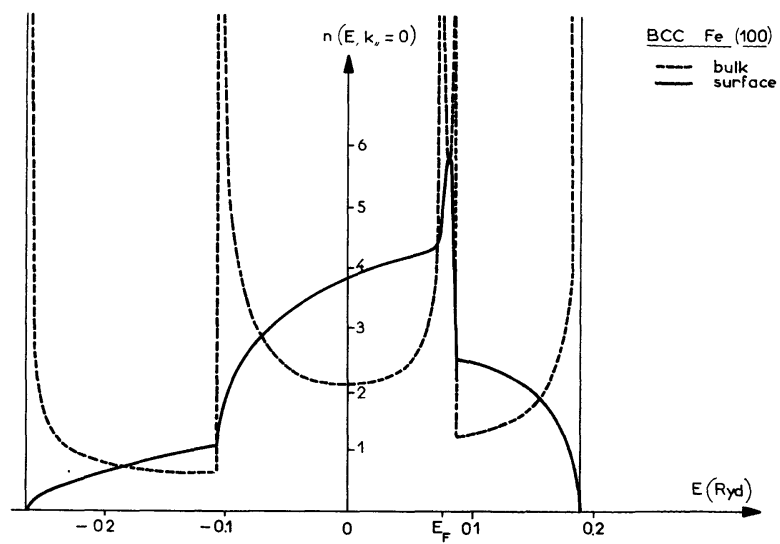

Fig. 4. - The local densities of states with no momentum parallel to the (100) plane for bcc $\mathrm{Fe}$ : bulk case (broken curve) and surface case (full curve).

$\mathrm{Ni}$ [1] is explained. In addition, the peak of surface states that we have obtained for a (100) cleaved bcc $\mathrm{Fe}$ crystal is quite consistent with the observation that has been made of a similar peak on the same face of $\mathbf{W}[2,3]$ and Mo [4].

\section{References}

[1] Hagstrum, H. D. and Becker, G. E., Phys. Rev. 159 (1967) 572.

[2] Plummer, E. W. and Gadzuk, J. W., Phys. Rev. Lett. 25 (1970) 1493.

[3] Feuerbacher, R. B. and Fitton, B., Phys. Rev. Lett. 29 (1972) 786 ; Phys. Rev. Lett. 30 (1973) 923.

[4] Al Khoury Nemeh, E., Cinti, R. C. and Hudson, J. B., J. Physique Lett. 35 (1974) L-179.

[5] Kalkstein, D. and Soven, P., Surf. Science 26 (1971) 85.

[6] Allan, G. and Lenglart, P., Surf. Science 30 (1972) 641.
[7] Cyrot-Lackmann, F. and Desjonquères, M. C., Surf. Science 40 (1973) 423.

[8] Cyrot-Lackmann, F., Desjonquères, M. C. and GasPARD, J. P., J. Phys. C 7 (1974) 925.

[9] Haydock, R. and Kelly, M. J., Surf. Science 38 (1973) 139.

[10] PEnN, D. R., Surf. Science 38 (1973) 333.

[11] Gaspard, J. P. and Cyrot-Lackmann, F., J. Phys. C 6 (1973) 3077.

[12] Desjonquères, M. C. and Cyrot-Lackmann, F., submitted to Phys. Rev.

[13] Sturm, K. and Feder, R., Solid State Commun. 14 (1974) 1317. 